\title{
PERSEPSI MASYARAKAT SUKU BAJAU TENTANG KELESTARIAN LINGKUNGAN HIDUP DI DESA BUNGIN PERMAI KECAMATAN TINANGGEA KABUPATEN KONAWE SELATAN
}

\author{
Putu Riris Elsha Pratiwi ${ }^{1}$
}

\begin{abstract}
${ }^{1}$ Alumni Pendidikaan Geografi FKIP UHO
Abstrak: Penelitian berjudul Persepsi Masyarakat Suku Bajau Tentang Kelestarian Lingkungan Hidup di Desa Bungin Permai Kecamatan Tinanggea Kabupaten Konawe Selatan. Penelitian ini bertujuan untuk mengetahui persepsi msyarakat suku Bajau tentang kelestarian lingkungan hidup di Desa Bungin Permai Kecamatan Tinanggea Kabupaten Konawe Selatan. Metode yang di gunakan dalam penelitian ini yaitu menggunakan deskriptif kualitatif. Hasil penelitian diketahui bahwa persepsi masyarakat suku Bajau tentang kelestarian lingkungan hidup di Desa Bungin Permai adalah tergolong dalam kategori cukup baik dengan jawaban responden pada kisaran 3.03 yang diperoleh dari perhitungan rata-rata kumulatif dari 4 variabel indikator yaitu pengetahuan dasar masyarakat suku Bajau tentang kelestarian lingkungan hidup adalah tergolong dalam kategori kurang baik dengan jawaban responden berkisar pada 2.91, dan pemahaman masyarakat suku Bajau tentang manfaat lingkungan hidup dan kelestariannya tergolong cukup baik yaitu jawaban responden pada kisaran 3.15, sedangkan tanggapan masyarakat suku Bajau tentang pengelolaan lingkungan hidup dan kelestariannyadi Desa Bungin Permai Kecamatan Tinanggea Kabupaten Konawe Selatan adalah berada pada kategori kurang baik yaitu dengan jawaban responden berkisar pada nilai 2.99, serta kepercayaan masyarakat suku Bajau tentang faktor-faktor penyebab yang menimbulkan kerusakan lingkungan hidup dan kelestariannya di Desa Bungin Permai Kecamatan Tinanggea Kabupaten Konawe Selatan berada pada kategori cukup baik dengan nilai pada kisaran 3.07.Kesimpulan penelitian ini persepsi masyarakat suku bajau tentang kelestarian lingkungan hidup di Desa Bungin Permai kecamatan Tinanggea Kabupaten Konawe Selatan secara umum dalam kategori cukup baik.
\end{abstract}

Kata Kunci: Persepsi, Masyarakat Suku Bajau, Lingkungan Hidup 


\title{
BAJAU TRIBAL SOCIETY PERCEPTIONS ABOUT ENVIRONMENTAL SUSTAINABILITY IN BUNGIN PERMAI VILLAGE TINANGGEA SUB- DISTRICT OF SOUTH KONAWE REGENCY
}

\author{
Putu Riris Elsha Pratiwi ${ }^{1}$ \\ ${ }^{1}$ Geography Educational Alumni Halu Oleo University
}

\begin{abstract}
Research entitled Bajau Tribal Society Perceptions about Environmental Sustainability in Bungin Permai Village Tinanggea Sub-district of South Konawe Regency. This study aims to determine the perception of msyarakat Bajau tribe about environmental sustainability in the Village Bungin Permai District Tinanggea South Konawe Regency. The method used in this research is using qualitative descriptive. The result of the research shows that Bajau people's perception about environmental sustainability in Bungin Permai Village is classified as good enough with respondent's answer in the range of 3.03 obtained from calculation of cumulative average of 4 indicator variables that is basic knowledge of Bajau society about environmental sustainability is classified in the category of less good with respondents answer ranges from 2.91, and understanding of the Bajau tribe about environmental benefits and its sustainability is quite good that respondents answer in the range 3.15, while the Bajau people's response about environmental management and sustainability in Bungin Permai Village Tinanggea Sub- Konawe Selatan Regency is in the less favorable category with respondents answer ranging from 2.99, as well as the belief of Bajau tribe people about causal factors causing environmental damage the dance in the village of Bungin Permai Tinanggea subdistrict of South Konawe Regency is in good enough category with a value in the range of 3.07. Conclusion of this research is the perception of Bajau tribe community about environmental sustainability in Bungin Permai Village Tinanggea sub-district of South Konawe Regency in general in good enough category.
\end{abstract}

Keywords: Perception, Bajau Tribe Society, Living Environment

\section{PENDAHULUAN}

Suku Bajau dikenal sebagai
masyarakat yang hidupdiwilayah
pesisir. Suku Bajaubanyak ditemukan
di pesisir Sulawesi Tenggara, yang
tersebar dibeberapa kabupaten dan
kota diantaranyadipesisir kota
Kendari, diwilayah pesisir Kabupaten
Muna, Buton, Kolaka, Konawedan
Kepulauan Wakatobi (Wangi-wangi,
Kaledupa, Tomia dan Binongko). Data
tahun 1991 memperkuat terdapat
350.000 jiwa suku Bajau yang tersebar

di Sulawesi Tenggara yang umumnya 99\% sebagai nelayan dan berada dalam taraf hidup dibawah garis kemiskinan (I Ketut Suardika, 2015 dalam Alimaturahim, 1991:5).

Berdasarkan penelitian awal
diperoleh gambaran mengenai
kehidupan masyarakat suku bajau di
Desa
Permai.KehidupanSukuBajau di Desa
Bungin Permai memang masih
terbilang sangatsederhana.Dilihat dari
segi mata pencaharian, masyarakat

Putu Riris Elsha Pratiwi 
suku Bajau sebagian besar bekerja sebagai nelayan. Jika dilihat dari segi pendidikan, sebagianbesar darimereka hanya menempuh pendidikan hingga jenjang Sekolah Dasar (SD) sehingga hal tersebut akan berdampak pada rendahnya kualitas sumber daya manusia yang ada pada masyarakat suku Bajau. Jika dilihat dari sisi lain, masyarakat suku Bajau adalah masyarakat yang kurang memahami tentang arti penting lingkungan hidup.

Masyarakat suku Bajau di Desa Bungin Permaidimasa sekarangtelah menunjukan perubahan pada pola kehidupan sosial mereka. Perubahan sosial yang begitu cepat pada masyarakat suku Bajau tidak lantas pula diikuti oleh perubahan sikap masyarakat terhadap kesadaran dalam memanfaatkan dan melestarikan lingkungan karena masyarakat suku Bajau yang mayoritas bermatapencaharian sebagai nelayan akan senantiasa berhubungan langsung dengan laut dalam menjalankan segala aktivitasnya sehari-hari. Bila hal ini tidak dibarengi dengan pengetahuan dan pemahaman dalam hal memanfaatkan dan melestarikan lingkungan hidup, maka akan berdampak pada kerusakan dan penurunan kualitas lingkungan terutama pada wilayah laut atau pesisir yang menjadi objek aktivitas seharihari masyarakat suku Bajau. Desa Bungin Permai terbagi menjadi 4 (empat) dusun yang secara keseluruhan jumlah penduduknya mencapai 1403 jiwa dari 310 kepala keluarga.

Kata persepsi berasal dari unsur kata serapan bahasa inggris yaitu perception. Kata perception diterjemahkan dalam bahasa indonesia sebagai pandangan, perasaan, daya penglihatan/daya tangkap, pengetahuan, kesadaran, pengamatan, penglihatan. Pandangan ini memiliki pemahaman yang berbeda-beda, sehingga secara logis persepsi atau pandangan seseorang tentang sesuatu masalah atau objek tertentu adalah sama. Banyak stimulus yang di hadapi seseorang dalam waktu tertentu yang relative bersamaan menuntut orang yang bersangkutan untuk menyeleksinya.

Menurut Kartini (2001:67) mengatakan Persepsi adalah pandangan interprestasi seseorang atau individu terhadap suatu kesan objek yang diinformasikan kepada dirinya dan lingkungan tempat ia berada sehingga dapat menentukan tindakannya. Selanjutnya Menurut Dahuri dalam Sudarmi (2012:20) bahwa masyarakat pesisir adalah masyarakat yang bermukim disepanjang kawasan peralihan (interface area) antara ekosistem darat dan laut dengan batas terluar $20 \mathrm{~km}$ dari garis pantai atau berada sejauh 4 mil atau 12 mil dari garis pantai ke arah laut.

Menurut Ketut Suardika dalam Galib L. M (2001), suku Bajau sering disebut dengan berbagai macam nama, seperti di Kawasan Timur Indonesia disebut Bajau, dikawasan Barat Indonesia suku ini disebut Rakyat Laut, Orang Laut atau Suku Laut. Sementara di Malaysia Barat atau di Johor Selatan mereka disebut Orang Laut dan di Johor Utara mereka disebut Orang Kuala. Meskipun suku bangsa ini memiliki nama yang berbeda-beda berdasarkan geografis tempat tinggalnya, tetapi dari segi budaya mereka memiliki banyak persamaan khususnya pola pemukiman yang 
umumnya dilaut atau di pesisir pantai,kegiatan mata pencaharian sebagai nelayan tradisional. Berdasarkan persamaan budaya ini, dapat dinyatakan bahwa mereka berasal dari rumpun yang sama.

Dalam Undang-Undang Nomor 23 Tahun 1997 tentang Pengelolaan Lingkungan Hidup disebutkan bahwa lingkungan hidup adalah kesatuan ruang dengan semua benda, daya, keadaan, dan makhluk hidup, termasuk manusia dan perilakunya yang memengaruhi kelangsungan peri kehidupan dan kesejahteraan manusia serta makhluk hidup lain.

Marulita Yuliana Sidabukke dalam Munadjad Danusaputro (1981: 62) ahli hukum lingkungan terkemuka dan guru besar hukum lingkungan Universitas Padjajaran mengartikan lingkungan hidup sebagai semua benda dan kondisi, termasuk didalamnya manusia dan tingkah perbuatannya, yang terdapat dalam ruang tempat manusia berada dan mempengaruhi hidup serta kesejahteraan manusia dan jasad hidup lainnya.

Menurut Kuswardoyo (2009: 186-193) ada beberapa macam kerusakan lingkungan hidupyang terjadi di daerah peisir pantai yaitu pencemaran lingkungan yang dilakukan manusia berupa pembuangan sampah cair ke laut seperti sisa deterjen, sisa minyak, penebangan hutan bakau, pemakaian bahan peledak dalam melakukan penangkapan ikan, reklamasi pantai dan juga kerusakan yang disebabkan oleh alam seperti letusan gunung api, gempa bumi, badai siklon dan kerusakan akibat banjir rob maupun tsunami.

\begin{abstract}
Menurut Adji Samekto
(2003:4), perlindungan dan pengelolaan lingkungan hidup diindonesia, secara mendasar diatur dalam UU No. 32 Tahun 2009 tentang Pengelolaan dan Perlindungan Lingkungan Hidup. Tujuan dan sasaran utama dari ketentuanketentuan yang tertuang dalan undangundang dimaksud adalah pengelolaan secara terpadu pada pemanfaatan, pemulihan dan pengembangan lingkungan hidup. Tujuan dan sasaran utama tersebut, sedikit banyak dilatarbelakangi oleh adanya kenyataan bahwa telah terjadi eksplorasi dan eksploitasi tiak mengenal batas oleh manusia terhadap sumber daya alam yang mengakibatkan rusak dan tercemarnya lingkungan hidup.
\end{abstract}

\section{METODOLOGI PENELITIAN}

\section{Jenis Penelitian}

Jenis penelitian ini adalah penelitiandeskriptifkualitatif.

\section{Waktu dan Tempat Penelitian}

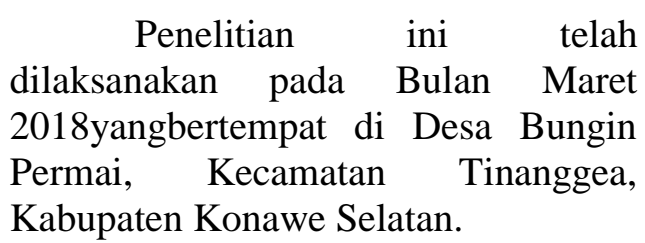

\section{Populasi dan Penentuan Sampel}

Sugiyono

$(2007: 148)$

mengemukakan bahwa populasi adalah wilayah generalisasi yang terdiri atas: objek/subyek yang mempunyai kualitas dan karakteristik tertentu yang ditetapkan oleh peneliti untuk dipelajari dan kemudian ditarik kesimpulannya. Adapun yang menjadi populasi dalam penelitian ini adalah 
masyarakat suku Bajau yang ada di Desa Bungin Permai.Berdasarkan data yang ada di kantor Desa Bungin Permai, Kecamatan Tinanggea, Kabupaten Konawe Selatan yaitu sebanyak 310 Kepala Keluarga.

Sampel adalah bagian dari jumlah dan karakteristik yang dimiliki oleh populasi tersebut, Sugiono (2007:149). Dalam rangka mempermudah melakukan penelitian maka diperlukan suatu sampel penelitian yang ketika populasi yang diteliti berjumlah besar atau banyak. Agar memperoleh sampel yang representatif dari populasi, maka dalam populasi diupayakan untuk memiliki peluang untuk menjadi sampel.

\section{Instrumen Penelitian}

Instrumen penelitian digunakan sebagai acuan dalam pengumpulan data yang dilakukan dengan membagikan daftar pernyataan berupa kuisioner kepada responden untuk mendeskripsikan persepsi masyarakat suku Bajau tentang kelestarian lingkungan hidup di Desa Bungin Permai, Kecamatan Tinanggea, Kabupaten Konawe Selatan.

\section{Jenis Data dan Sumber Data}

Jenis data yang digunakan dalam penelitian ini adalah data primer dan data sekunder.

\section{Teknik Pengumpulan Data}

Dalampeknikpengumpulan
data yang
akandigunakanadalahobservasi,
angket, danokumentasi.

\section{Teknik Analisis Data}

Teknikanalisis data yang digunakanadalahteknikanalisiskualitati f.Analisis data kualitatifmerupakantatacarapenelitian yang menghasilkan data deskriptif.

\section{GAMBARAN UMUM LOKASI PENELITIAN}

\section{Deskripsi Singkat Desa Bungin Permai}

BungindalambahasaBajaumeru pakansebutanuntukbumbunganpasirput ihmemanjangdiataspermukaan air laut.Bunginjugadiartikansebagaitempa kberlabuhatausinggahsementarawaktu. NamaBunginpertama kali diberikanolehManorang,

LalapadanRandah.masyarakatnyaberpr ofesisebagainelayan yang manasebagianmasyarakatmatapencaha rianyaadalahperikanandenganbudidaya tambakkarenasebagianbesarwilayahny amerupakanwilayahpesisirmakatamba kdanempangadalahmatapencaharianut ama di desaBunginPermai

\section{Kondisi Iklim}

\section{Daerah}

desa BunginPermaimemiliki ciri-ciri iklim yang sama dengan daerah lain di Sulawesi Tenggara yang umumnya beriklim Tropis dengan keadaan suhu berkisar $32^{\circ} \mathrm{C}$ dengan curah hujan sekitar 1500-3000 mm. Daerah ini memiliki 2 musim dalam setahun yaitu musim panas dan musim hujan. Musim hujan biasanya berlangsung dari bulan Desember sampai bulan Mei. 


\section{Keadaan Demografi}

Berdasarkan data yang
diperoleh dari Kepala desa
BunginPermai maka jumlah pnduduk
masyarakat desa Bungin Permai yaitu
berjumlah 1403 jiwa. Dengan jumlah
kepala keluarga sebanyak $310 \mathrm{KK}$.

Tingkat pendidikan memiliki peran penting dalam menentukan pendapat masyarakat dalam melihat persoalan yang ada di lingkunganya mencaup kesadaran dan kepedulian terhadap pentinya kesadaran terhadap kelestarian lingkungan. Selain itu tingkat pendidikan juga mempengaruhi presepsi masyarakat dalam memandang persoalan pendidikan formal dalam hubunganya kehidupan masyarakat di pesisir pantai desa BunginPermaiKecamatan Tinanggea Kabupaten Konawe Selatan.

Desa Bungin Permai sebagai
masyarakat maritim umumnya
masyarakatnya sebagian besar
menggantungkan hidupanya dengan
mata pencaharian sebagai nelayan.

Masyarakat yang berada dalam setiap wilayah diseluruh wilayah yang ada di Indonesia terdiri dari masyarakat yang herterogen sebagai bagian dari adanya transmigrasi dan mobilisasi penduduk secara sosial. Dalam kehidupan tersebut kemudian terjadi sosialisasi masyarakat yang satu dengan masyarakat yang lainya yang berasal dari daerah atau wilayah yang satu dengan daerah atau wilayah yang lainya. Hal yang sama juga terjadi di masyarakat desa BunginPermaiKecamatan Tinanggea Kabupaten Konawe Selatan yang teridiri dari beberapa suku yang mendiami desa Bungin Permai yang telah hidup bersama dana berdampingan satu sama lain.

\section{HASIL DAN PEMBAHASAN}

\section{Karakteristik Responden}

Berdasarkan penelitian dari 76 jumlah responden diperoleh informasi tingkat usia responden yang dipilih dalam penelitian ini berdasarkan tabel berikut ini:

Tabel 4.1.

Klasifikasi Umur Responden di DesaBungin Permai Kecamatan Tinanggea

\begin{tabular}{llll}
\hline No. & $\begin{array}{l}\text { Klasifikasi Umur } \\
\text { (Tahun) }\end{array}$ & $\begin{array}{l}\text { Jumlah Responden } \\
\text { (orang) }\end{array}$ & $\begin{array}{l}\text { Persentase } \\
(\%)\end{array}$ \\
\hline 1. & $20-40$ & 30 & 39.47 \\
$2 . \quad 41-60$ & 36 & 47.37 \\
$3 . \quad>61$ & 10 & 13.15 \\
\hline Jumlah & 76 & 100 \\
\hline
\end{tabular}

Sumber : Diolah dari hasil angket 2018

Dalam penelitian ini tingkat pendidikan yang dimaksud adalah tingkat pendidikan formal yang pernah ditempuh responden. Untuk lebih jelasnya tingkat pendidikan responden di Desa Bungin Permai disajikan pada Tabel 4.2. berikut: 
Tabel 4.2

Klasifikasi Responden Berdasarkan Tingkat Pendidikan di Desa Bungin Permai

\begin{tabular}{llll}
\hline No. & Tingkat Pendidikan & $\begin{array}{l}\text { Jumlah Responden } \\
\text { (orang) }\end{array}$ & $\begin{array}{l}\text { Persentase } \\
(\%)\end{array}$ \\
\hline 1. & Tidak Sekolah & 6 & 7.89 \\
2. & SD/Sederajat & 30 & 39.47 \\
3. & SMP/Sederajat & 20 & 26.31 \\
4. & SMA/ Sederajat & 10 & 13.15 \\
5. & Sarjana & 10 & 13.15 \\
& & & 100 \\
\hline Jumlah & 76 & \\
\hline
\end{tabular}

Sumber: Diolah dari hasil angket 2018

Pengetahuan Dasar Masyarakat Suku Bajau Tentang Lingkungan Hidup di DesaBungin Permai Kecamatan Tinanggea Kabupaten Konawe Selatan

$\quad$ Berdasarkanhasilanalisis data
yang
diperolehmelaluiangketpengetahuan
masyarakatsukuBajautentanglingkung

anhidup di DesaBunginPermaiKecamatanTinangg eaKabupatenKonawe Selatan, Secara kumulatif nilai rata-rata tentangpengetahuan masyarakatsukuBajauterhadap lingkunganhidupdankelestariannya di DesaBunginPermaiKecamatanTinangg eaKabupatenKonawe Selatan dapat dilihat pada tabel berikut:

Tabel. 4.3.Pengetahuan Masyarakat Suku Bajau TentangLingkungan Hidup

\begin{tabular}{|c|c|c|c|}
\hline No & $\begin{array}{l}\text { Indikator Pengetahuan Dasar Mayarakat } \\
\text { Suku Bajau Tentang Lingkungan } \\
\text { Hidup }\end{array}$ & $\begin{array}{l}\text { Nilai Rata-Rata } \\
\text { Indikator }\end{array}$ & Kategori \\
\hline 1. & $\begin{array}{l}\text { Pengetahuan masyarakat suku Bajau } \\
\text { tentang lingkungan hidup }\end{array}$ & 3.25 & \multirow{6}{*}{$\begin{array}{l}\text { Kurang } \\
\text { Baik }\end{array}$} \\
\hline 2. & $\begin{array}{l}\text { Pengetahuan masyarakat suku bajau } \\
\text { tentang komponen biotik lingkungan } \\
\text { hidup }\end{array}$ & 2.86 & \\
\hline 3. & $\begin{array}{l}\text { Pengetahuan masyarakat suku bajau } \\
\text { tentang komponen abiotik lingkungan } \\
\text { hidup }\end{array}$ & 2.78 & \\
\hline 4. & $\begin{array}{l}\text { Pengetahuan masyarakat suku bajau } \\
\text { tentang kondisi lingkungan hidup dapat } \\
\text { mempengaruhi keadaan ekonomi } \\
\text { masyarakat }\end{array}$ & 2.79 & \\
\hline 5. & $\begin{array}{l}\text { Pengetahuan masyarakattentang laut } \\
\text { dan masyarakatsuku Bajau adalah suatu } \\
\text { kesatuan yang tidak dapat dipisahkan }\end{array}$ & 2.87 & \\
\hline Tot: & Rata-Rata Kumulatif & 2.91 & \\
\hline
\end{tabular}

Sumber : Diolah dari hasil angket 2018 
Berdasarkan tabel di atas maka dapat diketahui nila rata-rata kumulaif dari 5 indikator di atas tentang pengetahuan masyarakat suku Bajau terhadap lingkungan hidup dandi Desa Bungin Permai Kecamatan Tinanggea Kabupaten Konawe Selatan sebesar 2.91. Maka dengan demikian dapat dipahami bahwa pengetahuan masyarakat suku Bajau terhadap lingkungan hidup dan di Desa Bungin Permai Kecamatan Tinanggea Kabupaten Konawe Selatan berada pada kategori kurang baik.

\section{Pemahaman Masyarakat Suku Bajau Tentang Manfaat Lingkungan Hidup di Desa Bungin Permai Kecamatan Tinanggea Kabupaten Konawe Selatan}

Lingkungan hidup sebagai tempat hidup manusia dengan mahluk lainya memiliki banyak manfaat bagi mahluk hidup dalam memenuhi kebutuhan hidupnya dengan potensi alam yang ada pada lingkungan. Berdasarkan hasil analisis data yang diperoleh melalui angket maka untuk lebih jelasnya tentang pemahaman masyarakat suku Bajau tentang manfaat lingkungan hidup di Desa Bungin Permai Kecamatan Tinanggea Kabupaten Konawe Selatan dapat dijabarkan berdasarkan indikatorindikator variabel dapat dilihat pada tabel berikut:

Tabel. 4.4.

Pemahaman Masyarakat Bajau TentangManfaat Lingkungan Hidup

\begin{tabular}{|c|c|c|c|}
\hline No & $\begin{array}{l}\text { Indikator Pemahaman Masyarakat } \\
\text { Tentang Manfaat Lingkungan Hidup }\end{array}$ & $\begin{array}{l}\text { Nilai Rata-Rata } \\
\text { Indikator }\end{array}$ & Kategori \\
\hline 1. & $\begin{array}{l}\text { Lingkungan hidup sebagai tempat hidup } \\
\text { manusia dan makhluk hidup lainya }\end{array}$ & 2.97 & \multirow{5}{*}{$\begin{array}{l}\text { Cukup } \\
\text { Baik }\end{array}$} \\
\hline 2. & $\begin{array}{l}\text { Sumber daya alam yang terkandung } \\
\text { dalam lingkungan hidup dapat } \\
\text { dimanfaatkan untuk kebutuhan hidup }\end{array}$ & 3.20 & \\
\hline 3. & $\begin{array}{l}\text { Lingkungan hidup sebagai penyedia } \\
\text { energi dan bahan bakar bagi manusia }\end{array}$ & 2.89 & \\
\hline 4 & $\begin{array}{l}\text { Air sebagai kebutuhan yang sangat } \\
\text { penting bagi mahluk hidup }\end{array}$ & 3.55 & \\
\hline \multicolumn{2}{|c|}{ Total Rata-Rata Kumulatif } & 3.15 & \\
\hline
\end{tabular}

Sumber : Diolah dari hasil angket 2018

Berdasarkan tabel atas maka dapat diketahui bahwa dari 4 indikor di atas pemahaman masyarakat suku Bajau tentang manfaat lingkungan hidup di Desa Bungin Permai Kecamatan Tinanggea Kabupaten Konawe Selatan secara kumulatif diperoleh nilai rata-rata kumulatif 3.15. Maka dengan demikian dapat dipahami bahwa pemahaman masyarakat suku Bajau tentang manfaat lingkungan hidup di Desa Bungin Permai Kecamatan Tinanggea Kabupaten Konawe Selatan dalam kategori cukup baik 
Tanggapan Masyarakat Suku Bajau Tentang Pengelolaan Lingkungan Hidup di Desa Bungin Permai Kecamatan Tinanggea Kabupaten Konawe Selatan

Manusia memiliki tanggung jawab besar dan sangat penting dalam menjaga pengelolaan lingkungan hidup. Peran manusia dalam menjaga kelestarian lingkungan hidup adalah konsekuensi dari hubungan interdepedensi antara manusia dan lingkungan hidup yang saling membutuhkan.

Berdasarkanhasilanalisis data yang diperolehmelaluiangketmakauntuklebi hjelasnyatentangtanggapanmasyarakat sukubajautentangpengelolaan lingkungan hidup dan kelestariannya di

DesaBunginPermaiKecamatanTinangg eaKabupatenKonawe Selatan dapatdijabarkanberdasarkanindikatorindikatorvariabel.Secara kumulatif rata-rata tanggapan masyarakat suku bajau tentang pengelolaan lingkungan hidup dan kelestariannyadi DesaBunginPermaiKecamatanTinangg eaKabupatenKonawe Selatan dapat dilihat pada tabel berikut:

Tabel. 4.5.

Tanggapan Masyarakat Suku Bajau Tentang Pengelolaan Lingkungan Hidup dan Kelestariannya

\begin{tabular}{|c|c|c|c|}
\hline No & $\begin{array}{l}\text { Indikator tanggapan masyarakat suku } \\
\text { bajau tentang pengelolaan lingkungan } \\
\text { hidup dan kelestariannya }\end{array}$ & $\begin{array}{l}\text { Nilai Rata-Rata } \\
\text { Indikator }\end{array}$ & Kategori \\
\hline 1. & $\begin{array}{l}\text { Kualitas lingkungan hidup tergantung } \\
\text { pengelolaan manusia dalam menjaganya }\end{array}$ & 3.04 & \multirow{8}{*}{$\begin{array}{l}\text { Kurang } \\
\text { Baik }\end{array}$} \\
\hline 2. & $\begin{array}{l}\text { Lingkungan yang bersihmempengaruhi } \\
\text { kesehatan masyarakatmenjadi lebih baik }\end{array}$ & 3.32 & \\
\hline 3. & $\begin{array}{l}\text { Lingkungan yang bersih dan indah } \\
\text { membuat suatu daerah lebih nyaman } \\
\text { untuk ditinggali }\end{array}$ & 3.11 & \\
\hline 4. & $\begin{array}{l}\text { Lingkungan hidup perlu dilestarikan agar } \\
\text { daya dukung lingkungan tetap } \\
\text { berkelanjutan }\end{array}$ & 2.99 & \\
\hline 5. & $\begin{array}{l}\text { Penanaman pohon bakau di pesisir pantai } \\
\text { bermanfaat bagi biota laut dan dapat } \\
\text { menahan terjadinya abrasi pantai }\end{array}$ & 3.07 & \\
\hline 6. & 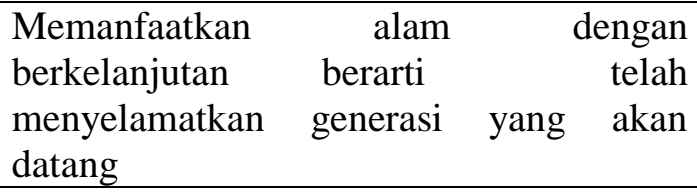 & 2.88 & \\
\hline 7. & $\begin{array}{l}\text { Peranan masyarakat lebih utama dari pada } \\
\text { pemerintah dalam menjaga kelestarian } \\
\text { lingkungan. }\end{array}$ & 2.99 & \\
\hline \multicolumn{2}{|c|}{ Total Rata-Rata Kumulatif } & 2.99 & \\
\hline
\end{tabular}

Sumber : Diolah dari hasil angket 2018

Berdasarkan tabel di atas maka dapat diketahui bahwa dari 7 indikor di atas tentang tanggapan masyarakat suku bajau tentang pengelolaan 
lingkungan hidup dan kelestariannyadi Desa Bungin Permai Kecamatan Tinanggea Kabupaten Konawe Selatan secara kumulatif diperoleh nilai ratarata kumulatif 2.99. maka dengan demikian dapat dipahami bahwa tanggapan masyarakat suku bajau tentang pengelolaan lingkungan hidup dan kelestariannyadi Desa Bungin Permai Kecamatan Tinanggea Kabupaten Konawe Selatan dalam kategori kurang baik.

\section{Kepercayaan Masyarakat Bajau Tentang Faktor Penyebab Kerusakan Lingkungan Hidup dan Kelestarianya di Desa Bungin Permai Kecamatan Tinanggea Kabupaten Konawe Selatan}

Kerusakan yang terjadi pada lingkungan hidup tentu dipengaruhi oleh berbagai faktor baik yang bersifat alamiah maupun akibat aktifitas manusia yang tidak memperdulikan pentingnya kelestarian lingkungan hidup sebagai tempat hidup. Faktor yang mempengaruhi kerusakan lingkungan hidup khsusnya wilayah kawasan pesisir yang terjadi karena faktor alamiah yaitu faktor gelombang air laut yang menyebabkan abrasi, faktor bencana alam dan lain-lain. Sedangkan faktor penyebab kerusakan lingkungan hidup yang disebabkan oleh manusia adalah dipengaruhi oleh tingkat pengetahuan dan kepedulian serta kepercayaan manusia pada lingkungan terhadap faktor-faktor yang dapat merusak lingkungan sebagai temapat hidup manusia.

Adapun lebih jelasnya mengenai faktor kepercayaan manusia khsusnya masyarakat suku bajau terhadap faktor-faktor yang dapat merusak lingkungan dapat dijabarkan melalui beberapa indikator.

Secara kumulatif tentang nilai rata-rata indikator pada variabel kepercayaan masyarakat bajau tentang faktor penyebab kerusakan lingkungan hidup dan kelestarianya di desa bungin Permai kecamatan tinanggea kabupaten konawe selatan dapat dirumuskan melalui tabel berikut:

Tabel. 4.6.

Kepercayaan Masyarakat Bajau Tentang Faktor Penyebab KerusakanLingkungan Hidup dan Kelestarianya

\begin{tabular}{|c|c|c|c|}
\hline No & $\begin{array}{l}\text { Indikator Kepercayaan } \\
\text { Lingkungan Hidup }\end{array}$ & $\begin{array}{l}\text { Nilai Rata- } \\
\text { Rata } \\
\text { Indikator }\end{array}$ & Kategori \\
\hline 1. & $\begin{array}{l}\text { MembuangSampahKe } \\
\text { LautDapatMenyebabkanPencemaranpadaLingkunganLaut }\end{array}$ & 3.20 & \multirow{5}{*}{$\begin{array}{l}\text { Cukup } \\
\text { Baik }\end{array}$} \\
\hline 2. & $\begin{array}{l}\text { Menangkapikandengan menggunakan bahan peledak } \\
\text { menimbulkan kerusakan pada ekosistem laut }\end{array}$ & 3.32 & \\
\hline 3. & $\begin{array}{l}\text { Pembuangan Limbah rumah tangga dan limbah cair Ke } \\
\text { Laut dapat Menyebabkan Pencemaran dan Kerusakan } \\
\text { Pada Lingkungan Laut }\end{array}$ & 2.83 & \\
\hline 4 & $\begin{array}{l}\text { Penebangan hutan bakau yang Berlebihan Akan } \\
\text { Menyebabkan Kerusakan Dilingkungan Laut dan Pesisir }\end{array}$ & 2.93 & \\
\hline Tot & l Rata-Rata Kumulatif & 3.07 & \\
\hline
\end{tabular}

Sumber : Diolah dari hasil angket 2018 
Beradasarkan tabel di atas menunjukan bahwa secara umum tentang kepercayaan masyarakat bajau tentang faktor penyebab kerusakan lingkungan hidup dan kelestarian di desa bungin Permai kecamatan tinanggea kabupaten konawe selatanadalah cukup baik. Berdasarkan nilai rata-rata kumulatif dari 4 indikator di atas yaitu membuang sampah dilaut dapat menyebabkan pencemaran di lingkungan laut, penangkapan ikan menggunakan peledak dapat menimbulkan kerusakan pada ekosistem laut, pembuangan limbah rumah tangga dan limbah cair dapat menyebabkan pencemaran dan kerusakan pada lingkungan laut, dan penebangan pohon bakau yang berlebihan dapat menyebabkan kerusakan lingkungan laut dan pesisir. Dari indikatortersebutmaka diperoleh nilai rata-rata kumlatif 3.07. Maka dengan demikian kepercayaan masyarakat bajau tentang faktor penyebab kerusakan lingkungan hidup dan kelestarian di desa bungin Permai kecamatan tinanggea kabupaten konawe selatan adalah berada pada kategori cukup baik.

Selanjutnya dalam pembahasan dan analisis data pada penelitian ini untuk menjawab rumusan masalah pada penelitian tentang persepsi mayarakat suku Bajau tentang kelestarian lingkungan hidup di Desa Bungin Permai Kecamatan Tinanggea Kabupaten Konawe Selatan secara kumulatif dari 4 variabel diperoleh tanggapan rata-rata jawaban responden dalam kategori cukup baik. Adapun nilai rata-rata kumulatif tentang presepsi mayarakat suku Bajau tentang kelestarian lingkungan hidup di Desa Bungin Permai Kecamatan Tinanggea Kabupaten Konawe selatan lebih jelasnya dapat dilihat pada tabel berikut:

Tabel. 4.7.

Persepsi Masyarakat Suku Bajau Tentang Kelestarian Lingkungan Hidup di Desa Tinanggea

\begin{tabular}{|c|c|c|c|}
\hline No & $\begin{array}{l}\text { Indikator Presepsi Masyarakat Suku Bajau Tentang } \\
\text { Kelestarian Lingkungan Hidup di Desa Bungin } \\
\text { Permai }\end{array}$ & $\begin{array}{l}\text { Nilai Rata-Rata } \\
\text { Indikator }\end{array}$ & Kategori \\
\hline 1. & $\begin{array}{l}\text { Pengetahuan Dasar Masyarakat Suku Bajau Tentang } \\
\text { Lingkungan Hidup di Desa Bungin Permai Kecamatan } \\
\text { Tinanggea Kabupaten Konawe Selatan }\end{array}$ & 2.91 & \\
\hline 2. & $\begin{array}{l}\text { Pemahaman Masyarakat Suku Bajau Tentang Manfaat } \\
\text { Lingkungan Hidupdi Desa Bungin Permai Kecamatan } \\
\text { Tinanggea Kabupaten Konawe Selatan }\end{array}$ & 3.15 & \\
\hline 3. & $\begin{array}{lcccr}\text { Tanggapan } & \text { Masyarakat } & \text { Suku } & \text { Bajau } & \text { Tentang } \\
\text { Pengelolaan Lingkungan Hidup } & \text { di Desa } & \text { Bungin } \\
\text { Permai Kecamatan Tinanggea Kabupaten } & \text { Konawe } \\
\text { Selatan }\end{array}$ & 2.99 & $\begin{array}{l}\text { Cukup } \\
\text { Baik }\end{array}$ \\
\hline 4 & $\begin{array}{l}\text { Kepercayaan Masyarakat Bajau Tentang } r \\
\text { Penyebab Kerusakan Lingkungan Hidup dan } \\
\text { Kelestarianya di Desa Bungin Permai Kecamatan } \\
\text { Tinanggea Kabupaten Konawe Selatan }\end{array}$ & 3.07 & \\
\hline \multicolumn{2}{|c|}{ Total Rata-Rata Kumulatif } & 3.03 & \\
\hline
\end{tabular}

Sumber : Diolah dari hasil angket 2018 
Berdasarkan tabel di atas maka dapat diketahui bahwa dari 4 Varibael di atas tentang persepsi masyarakat suku bajau tentang kelestarian lingkungan hidup di Desa Bungin Permai Kecamatan Tinanggea Kabupaten Konawe Selatan secara kumulatif diperoleh nilai rata-rata kumulatif 3.03. Maka dengan demikian dapat dipahami bahwa tanggapan masyarakat suku bajau tentang pengelolaan lingkungan hidup di Desa Bungin Permai Kecamatan Tinanggea Kabupaten Konawe Selatan dalam kategori cukup baik.

\section{PENUTUP}

\section{Kesimpulan}

Berdasarkan analisis data hasil penelitian dan pembahasan dalam penelitian ini maka penulis menyimpukan bahwa persepsi masyarakat suku Bajau Desa Bungin Permai Kecamatan Tinanggea Kabupaten Konawe Selatan dari tanggapan responden rata-rata kumulatif indikator variabel pada kisaran 3.03 masuk dalam kategori cukup baik berdasarkan analisis dan perhitungan kumulatif dari 4 variabel yaitu;

\section{Pengetahuan}

masyarakatsukuBajautentanglingkung anhidupdiDesaBunginPermaiKecamat anTinanggeaKabupatenKonawe

Selatan masih dalam kategori kurang baik dengan jawaban rata-rata kumulatif responden pada kisaran 2.91 .

2. Tanggapan masyarakat Bajau tentang manfaat lingkungan hidup di DesaBunginPermaiKecamatanTinangg eaKabupatenKonawe Selatan berada pada ketegori cukup baik dengan jawaban rata-rata kumulatif responden pada kisaran 3.15

3. Tanggapan masyarakat suku bajau tentang pengelolaan lingkungan hidupdi

DesaBunginPermaiKecamatanTinangg eaKabupatenKonawe Selatan yaitu berada pada kategori kurang baik dengan jawaban rata-rata kumulatif responden pada kisaran 2.99.

4. Kepercayaan masyarakat bajau tentang faktor penyebab kerusakan lingkungan hidup dan kelestarianya di desa bungin Permai kecamatan tinanggea kabupaten konawe selatan berada pada ketegori cukup baik dengan jawaban rata-rata kumulatif responden pada kisaran 3.07

\begin{tabular}{l}
\multicolumn{2}{c}{ Adapun saran } & dalam \\
penelitian ini sebagai bahan \\
rekomendasi dalam penelitian ini \\
yaitu:
\end{tabular}

\section{Kepada pihak Pemerintah}

Untuk memberikan perhatian serius kepada peningkatan kualitas sumber daya manusia agar meningkatkan pengetahuan tentang pentingnya kelestarian lingkungan hidup

\section{Kepada Masyarakat}

Agar lebih meningkatkan kesadaran terhadap pentingnya menjaga kelestarian lingkungan hidup karena sebagai tempat hidup yang saling ketergantungan antara manusia dan lingkunganya sebagai tempat hidup.

\section{Insan Akademik}

Untuk terus melakukan penelitian lanjutan tentang upaya dalam meningkatkan kesadaran masyarakat pesisir agar memimiliki kesadaran dalam mengelola dan melestarikan 
lingkungan hidup agar terus berkelanjutan.

\section{DAFTAR PUSTAKA}

Danusaputro, Munajat. 1981. Hukum Lingkungan Buku Umum 1. Jakarta: Bina Cipta.

Galib, L. M. 2001. Penerapan Model Konstruktif Pembelajaran Sains dan Teknologi dengan Pendekatan Sain -Teknologi Masyarakat. Disertasi Doktor pada PPs UPI Bandung: tidak diterbitkan.

Kartini, Kartono. 2001. Bimbingan Belajar. Jakarta: Rajawali.

Samekto, Adji. Studi Hukum Kritis: Kritik Terhadap Hukum Moderrn, Unversita.

Sugiyono. 2007. Metode Penelitian Kuantitatif Kualitatif dan $R \& D$. Bandung: CV. Alfabeta. 